\title{
DESIGN AND IMPLEMENTATION OF PI CONTROLLER IN A TWO TANK INTERACTING PROCESS USING LAB VIEW SOFTWARE
}

\author{
D. GAYATHRI, R. SUGANYA \& B. BALAJI \\ ${ }^{1,2}$ Assistant Professor, IFET College of engineering, India \\ ${ }^{3}$ Senior Assistant Professor, IFET College of engineering, India
}

ABSTRACT
In process industries, it is quite difficult to control the level of liquid in the tank.The processes having more than one
controlled loop are called as multiple input multiple output or multivariable process, which are very often found in
power plants, refinery processes, and chemical industries and in many industrial processes.The process with MIMO
system (Two tank interacting process) is difficult to control the multiple variables so the level of fluid in the tanks and
interaction between tanks need to be controlled. The problem of level control in interacting tank processes are system
dynamics and interacting characteristics. The PI controller is equipped with the MIMO system to obtain good
performance of the systemby using LABVIEW software.
KEYWORDS: Interacting Tank, LABVIEW \& PI Controller

Received: Jun 09, 2020; Accepted: Jun 29, 2020; Published: Aug 05, 2020; Paper Id.: IJMPERDJUN2020634

\section{INTRODUCTION}

Mathematical modeling gives a simple description of how the process reacts to various inputs. PI controllers areprominent in chemical industries and also it is easily accessible with standard components. For eminent attainment the PI controllers can deteriorate quite fast in nonlinear system. It is necessary to develop nonlinear PI controllers for controlling nonlinear processes.

\section{PROCESS DESCRIPTION}

Fig.1 shows the photograph of the laboratory level process station. It consists of three pumps, two motorized control valves, six process tanks, two overhead tanks, two differential pressure transmitters, five level transmitters and rotameters. Instrumentation panel consists of two PID controllers, main power supply switch, pump switches, motorized control valve switches and auxiliary switches for individual components. 


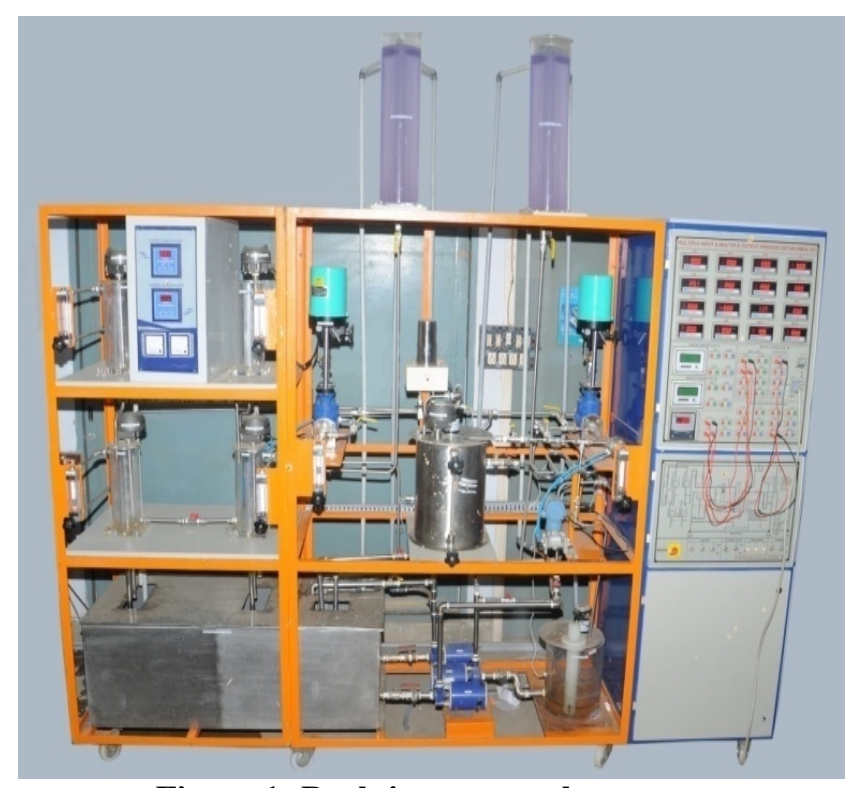

Figure 1: Real time two tank process

The Piping and Instrumentation Diagram of the coupled tank level process setup is shown in Figure 1 This process loop consists of two cylindrical tanks (T1 and T2) interconnected by a flow channel which causes the level of the two tanks to interact via HV25. Pump1 discharges water from reservoir to overhead tank (OHT1).T1 receives water from the overhead tank (OHT1) through the rotameters (R1 and R4) and motorized control valve (MCV1) via HV4. Pump 2 dischargeswater from reservoir to overhead tank (OHT2). T2 receives water from the overhead tank (OHT2) through the rotameters (R2 and R5) and motorized control valve (MCV2) via HV10.

The flow rate of water in the pipeline is indicated in rotameters. The Accumulation of the Process liquid in the tank is level in the tank. It is sensed by Capacitance level transmitter. The level transmitter output is in terms of current (420mA) and is given to VDAS-01 Data Acquisition Card. A digital control algorithm is developed and configured into the controller. The controller output is also a digital signal which is converted into the analog signal by DAC.

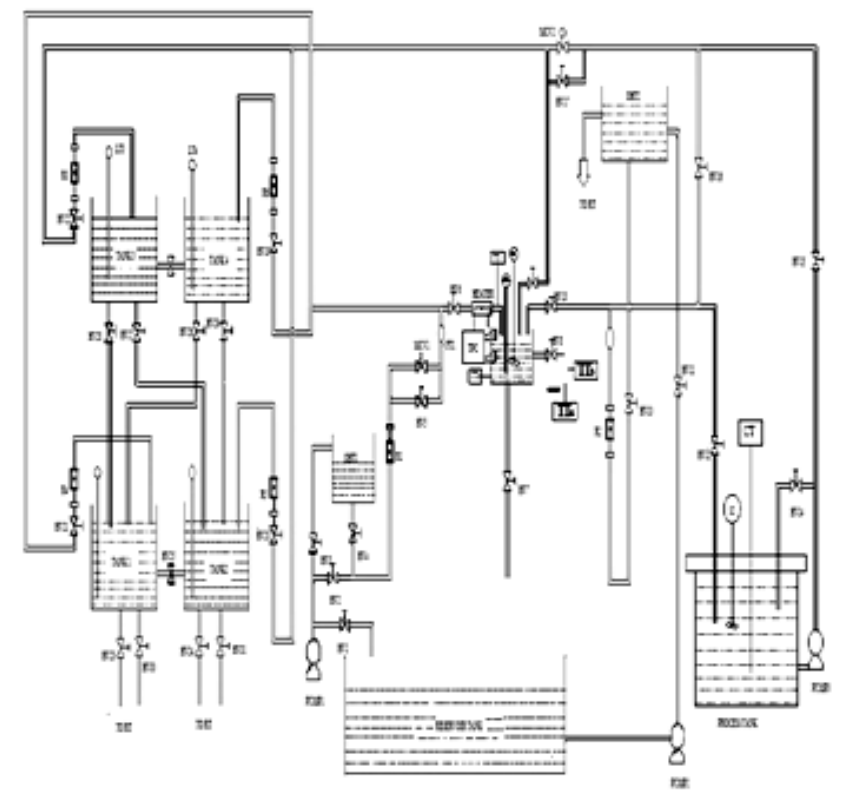

Figure 2: PI diagram of two tank interacting process. 
Mathematical Modelling of a Two-Tank Level Process

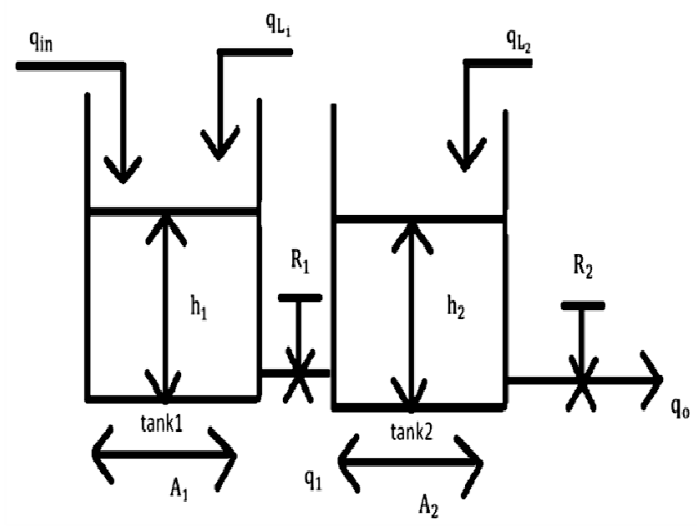

Figure 3: Mathematical Modelling of two tank interacting system

$$
\begin{aligned}
& \Lambda_{1} \frac{d H_{1}}{d t}=q_{\bar{D}-1}-q_{01}-q_{12} \\
& A_{2} \frac{d t_{2}}{d t}=q_{\bar{D} 2}-g_{02}+q_{12} \\
& A_{1} \frac{d h_{1}}{d t}=q_{i n 1}-c_{d} a_{1} \sqrt{2 g h_{1}}-c_{d} a_{12} \sqrt{2 g\left(h_{1}-h_{2}\right)} \\
& A_{2} \frac{d h_{2}}{d t}=q_{\text {in } 2}-c_{d} a_{2} \sqrt{2 g h_{2}}+c_{d} a_{12} \sqrt{2 g\left(h_{1}-h_{2}\right)} \\
& \frac{d h_{1}}{d t}=\frac{q_{\text {in } 1}}{A_{1}}-\frac{c_{d} a_{1}}{A_{1}} \sqrt{2 g h_{1}}-\frac{c_{d} a_{12}}{A_{1}} \sqrt{2 g\left(h_{1}-h_{2}\right)} \\
& \frac{d h_{2}}{d t}=\frac{q_{\text {in } 2}}{A_{2}}-\frac{c_{d} a_{2}}{A_{2}} \sqrt{2 g h_{2}}+\frac{c_{d} a_{12}}{A_{2}} \sqrt{2 g\left(h_{1}-h_{2}\right)}
\end{aligned}
$$

The finalized equation of tank process are

$$
\begin{aligned}
& h_{1}=\frac{R_{1}}{\tau_{1} s+1}\left[q_{i n 1}-q_{12}\right] ; \\
& h_{2}=\frac{R_{2}}{\tau_{2} s+1}\left[q_{i n 2}+q_{12}\right]
\end{aligned}
$$

\section{SPECIFIC COMPONENTS OF TWO TANK INTERACTING PROCESS}

PI controller setting of two tank process

\begin{tabular}{|l|l|}
\hline \multicolumn{1}{|c|}{ Description } & \multicolumn{1}{|c|}{ Quantity } \\
\hline Cross sectional area of the tank 1\& 2 $\left(A_{\mathrm{i}}\right)$ & $1130.4 \mathrm{~cm}^{2}$ \\
\hline Cross sectional area of the pipe outlet 1 \& 2 $\left(a_{\mathrm{i}}\right)$ & $3.9 \mathrm{~cm}^{2}$ \\
\hline
\end{tabular}




\begin{tabular}{|l|l|}
\hline Cross sectional area of the connecting pipe $\left(a_{12}\right)$ & $1.274 \mathrm{~cm}^{2}$ \\
\hline Maximum allowable height of the tank 1 \& $2\left(h_{\mathrm{i}}\right)$ & $0-25 \mathrm{~cm}$ \\
\hline Range of inflow rate for tank $1 \& 2$ & $0-100 \mathrm{LPH}$ \\
\hline Nominal inflow rate of $q_{\mathrm{in} 1}$ & $26 \mathrm{LPH}$ \\
\hline Nominal inflow rate of $q_{\mathrm{in} 2}$ & $20.75 \mathrm{LPH}$ \\
\hline Nominal level of $h_{1}$ & $12.6 \mathrm{~cm}$ \\
\hline Nominal level of $h_{2}$ & $12.1 \mathrm{~cm}$ \\
\hline Specific gravity $(g)$ & $9.81\left(\mathrm{~cm}^{2} / \mathrm{s}\right)$ \\
\hline Discharge co-efficient $\left(c_{\mathrm{d}}\right)$ & 0.6 \\
\hline
\end{tabular}

\begin{tabular}{|l|l|l|}
\hline MODE & $\mathbf{K}_{\mathbf{c}}$ & $\mathbf{T}_{\mathbf{i}}(\mathbf{s e c})$ \\
\hline PI & 1.87 & 0.666 \\
\hline
\end{tabular}

\section{SIMULATION RESULTS}

\section{Servo responses for two-tank interacting level process with PI controller}

The height of tank 1 and tank 2 is controlled with PI controller from 8 to $10 \mathrm{~cm}, 10$ to $8 \mathrm{~cm}$. Also corresponding changes in level $h_{1}$ and controller output $q_{i n}$. The controlled output of tank 1 and tank 2 is represented in the below figures 4,5 , and 6 .

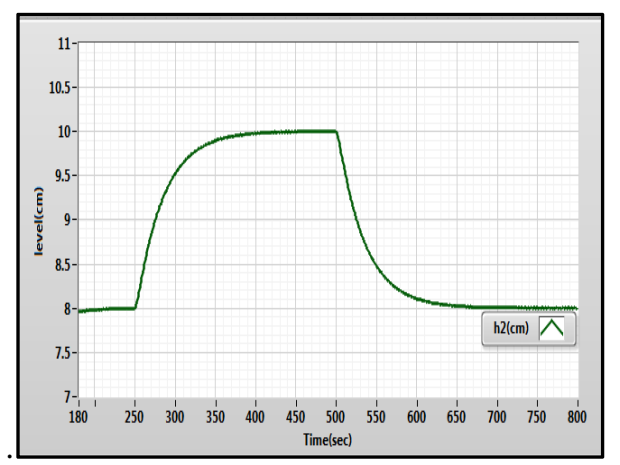

Figure 4: Servo response of level $h_{2}$ with PI controller.

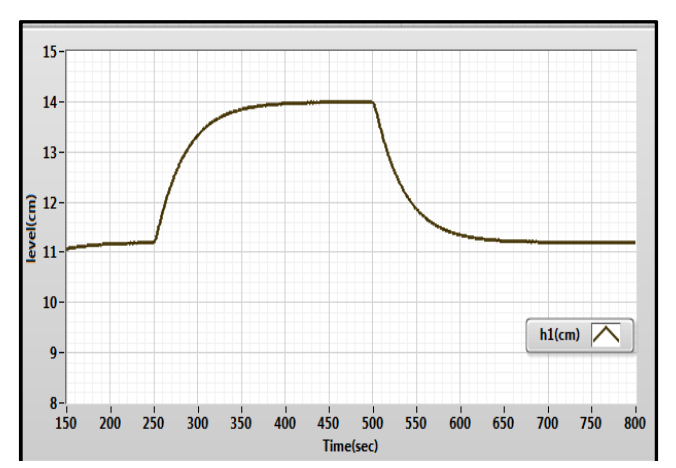

Figure 5: Response of level $h_{1}$ with PI controller.

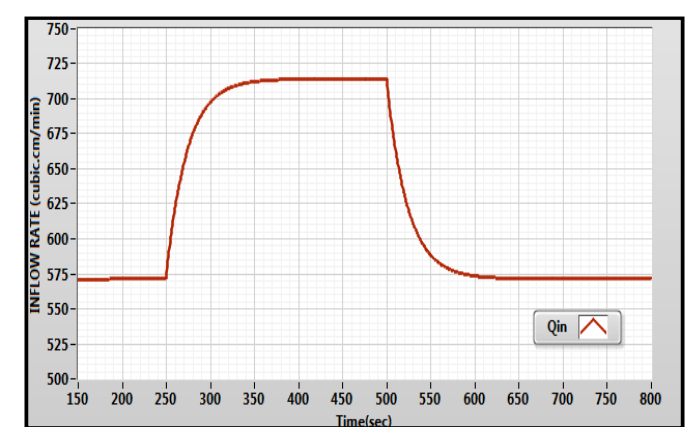

Figure 6: Response of PI controller output $\left(\mathrm{q}_{\mathrm{in}}\right)$. 
Performance Measures for Servo Response of Two Tank Interacting System

\begin{tabular}{|c|c|c|c|}
\hline Controller & Settling & Integral & square \\
\hline PI & 150 & 1520.8 & \\
\hline
\end{tabular}

\section{CONCLUSIONS}

White box model of interacting tank is equipped with PI controller to retain the height of two tanks T1 and T2.. The servo and regulatory responses were obtained with PI controller using Lab view software. The level of the tank is controlled by the PI controller and the performance is tabulated.

\section{REFERENCES}

1. George Stephanopoulos, “Chemical Process Control - An Introduction toTheoryand Practice”, PHI Learning Private Limited, New Delhi, 2009.

2. KUMAR, N. DINESH, et al. "BATTERY HEALTH MONITORING FOR MINI HYBRID POWER SYSTEM USING LABVIEW. International Journal of Electrical and Electronics Engineering Research (IJEEER) 3. 4, Oct 2013, 29-34

3. Jovitha Jerome, “Virtual instrumentation using LabVIEW”,PHI Learning Private Limited, New Delhi,2010.

4. Peelamedu, Coimbatore. "ANALYSIS OF A PART USING DYNAMIC SIMULATION AND REAL TIME EXPERIMENTS IN PART FEEDERS."International Journal of Mechanical and Production Engineering Research and Development (IJMPERD) 8. 5, Oct 2018, 133-142

5. Harshkaji,ShrutiAnnigeri and PrafullaPatil, "Designing PID Controller using Lab VIEW for Controlling Fluid Level of Vessel", International Journal of Engineerig Research and Applications(IJERA), ISSN:2248-9622,Vol.3,Issue2,pp.13291333,March-April2013.

6. Khan, Sher Afghan, et al. "Flow control with aero-spike behind bluff body."Int. J. Mech. Prod. Eng. Res. Dev.(IIJMPERED) 8.3 (2018): 1001-1008.

7. N.Deepa and S.Arulselvi, “Modeling and Intelligent Control of Two Tank Level Process", International Journal of Recent Technology and Engineering and Innovative Technology (IJRTE), ISSN: 2277-3754, Volume-3, Issue-9, pp.97- 106, March 2014. 

